\title{
Promising Antifungal Effect of Rice (Oryza sativa L.), Oat (Avena sativa L.) and Wheat (Triticum aestivum L.) Extracts
}

Fernanda Arnhold Pagnussatt (Corresponding author)

Food Science Laboratory, Chemistry and Food School, Food Science and Engineering PostGraduation Program, Rio Grande Federal University (FURG), Brazil

Tel: 55 (53) 32338663. E-mail: nandapagnu@terra.com.br

\section{Cristiana Costa Bretanha}

Food Science Laboratory, Chemistry and Food School, Food Science and Engineering PostGraduation Program, Rio Grande Federal University (FURG), Brazil

\section{Larine Kupski}

Food Science Laboratory, Chemistry and Food School, Food Science and Engineering PostGraduation Program, Rio Grande Federal University (FURG), Brazil

\section{Jaqueline Garda-Buffon}

Food Science Laboratory, Chemistry and Food School, Food Science and Engineering PostGraduation Program, Rio Grande Federal University (FURG), Brazil

\section{Eliana Badiale-Furlong}

Food Science Laboratory, Chemistry and Food School, Food Science and Engineering PostGraduation Program, Rio Grande Federal University (FURG), Brazil

Received: March 20, 2013 Accepted: May 20, 2013 Published: May 21, 2013

Doi: 10.5296/jab.v1i1.3452 URL: http://dx.doi.org/10.5296/jab.v1i1.3452 


\section{Abstract}

The antifungal activity from rice, oat and wheat crude proteic extracts on the development of Fusarium graminearum CQ244, Aspergillus flavus CCT 1217 and Rhizopus oryzae CCT 7560 was investigated intending to identify their potential as natural fungicides. The crude proteic extracts from cereals were prepared in ethanol and the antifungal properties were evaluated using the glucosamine, produced by the biomass as a response. F. graminearum was inhibited by wheat extracts, while that $A$. flavus was inhibited by oat extracts. $R$. oryzae was few inhibited. Proteic extracts in higher concentrations may be applied in field and/or storage, as natural antifungal.

Keywords: Cereal, Proteic extracts, Antifungal activity, Enzyme inhibitors

\section{Introduction}

The grains contamination is inevitable and many biotic and abiotic factors affect this. Many species are toxigenic and among them the Aspergillus and Fusarium are also phytopathogenic, causing diseases that are difficult to control in cereal crops (Dambolena et al., 2012; Lee et al., 2007). The knowledge about natural resistence against specific fungal genus and its location in the vegetable might be a strategic way to control the contamination problem (Armando et al., 2013). Some researchers have attempted to find these natural compounds products with antifungal effects for proper that might be recovery from wastes as interesting possibility, for economic and environment benefits (Pagnussatt et al., 2012b; Viuda-Martos et al., 2008). Then, simple tools for identify this properties are very useful to technology development preventing crops environment and human health damage (Zao et al., 2010; Del Río et al., 2003).

Among the compounds naturally present in plants tissues, some inhibit the microbial activity, such as alpha-amylase inhibitors which can alter fungal growth (Pagnussatt et al., 2012a; Pagnussatt et al., 2011a; Figueira et al., 2003). Others proteic compounds are being related to the expression of the biosynthesis regulatory gene, or even block the activity of the enzyme in the microorganism or insects metabolism (Lee et al., 2007; Kadozawa et al., 2002). The screening of these natural antifungal compounds is the first step to select a variety but recovery them from cereal wastes (Velutti et al., 2004), allowing a sustainable agriculture and promoting environmental quality is not a frequent evaluation. However, this would be a promising alternative to limit the fungal contamination.

The antimicrobial activity can be determined by in vitro or application tests. In the screening method, the crude compounds under study are applied directly on the product and provide preliminary information about its defense potential. In other type the antimicrobial agent is applied directly in a culture media and its effect is evaluated by hyphae inhibition or chemical fungal constituent's production (Del Río et al., 2003).

The glucosamine (GlcN, 2-amino-2-deoxy-D-glucose) and its acetylated form, $\mathrm{N}$-acetylglucosamine (GlcNAc, 2-acetamido-2- deoxy-D-glucose) are constituted by chitin and chitosan units. These compounds are synthesized by yeastor fungi species and had being used as microorganism growth indicator (Sitanggang et al., 2010). Each especies produced glucosamine in according to it biomass characteristics, but in any case the glucosamine increase is related to biomass evolution (Souza et al., 2011). In this work, the glucosamine 
production was chosen as indicator of the extract effect because it provides information about the fungal multiplication under different medium conditions (Del Río et al., 2003).

To our knowledge, there is not yet any published study on the use of proteic compounds obtained from rice, oat and wheat to prevent fungal contamination in order to recovery them. In this paper, we report the preliminary results of the antifungal activity evaluation from rice (Oryza sativa L.), oat (Avena sativa L.) and wheat (Triticum aestivum L.) crude proteic extract on the development of Fusarium graminearum CQ244, Aspergillus flavus CCT1217 and Rhizopus oryzae CCT7560, intending to screen their natural defense potential against fungal contamination and so establish a process to recovery and apply them in many steps of the productive chain.

\section{Materials and Methods}

\subsection{Fungal species}

Rhizopus oryzae (CCT 7560) and Aspergillus flavus (CCT 1217) were obtained from the Tropical Collection Andre Tosello Foundation (São Paulo, Brazil) and Fusarium graminearum (CQ 244) from the Phytopatology Department of Federal University of Rio Grande do Sul collection (Porto Alegre, Brazil). They were kept on potato-dextrose-agar (PDA) slants at 30 and $22{ }^{\circ} \mathrm{C}$ during 7 days.

\subsection{Crude Proteic Extracts}

Rice (Oryzae sativa L.) cultivar BR 424, oat (Avena sativa L.) cultivar UPFA 22 Temprana and wheat (Triticum aestivum L.) cultivar Safira were grounded until a 42 mesh particle size and the whole cereal was employed. The samples were stored during 6 months at $4{ }^{\circ} \mathrm{C}$ in sealed bag. The inhibitors extraction from oat and wheat was carried out with ethanol $12 \mathrm{mM} \mathrm{L}^{-1}$ at the ratio of 1:5 (w/v), during 12 hours, and ethanol $16 \mathrm{mM} \mathrm{L}^{-1}$ during 7 hours to rice samples (Pagnussatt et al., 2011a). The alcoholic proteic extracts were dried under nitrogen, and dissolved in sterile water, homogenizing in an ultrasonic bath. Different aliquots were added on each plate in order to obtain a final soluble protein concentration of $40 \mathrm{mg}$ (based on $\mathrm{IC}_{50}$ ) to evaluate their antifungal properties. The protein content in the extracts was carried out by Lowry method (1951).

\subsection{Protein Fractionation Procedures}

Samples of rice, oat and wheat were subjected to successive extractions with each of the following solvents: distilled water to extraction albumin, $1 \%$ sodium chloride solution for globulin, $70 \%$ ethanol solution for prolamins and $0.4 \%$ sodium hydroxide solution for glutelins. Distilled water $(10 \mathrm{ml})$ was added to $1 \mathrm{~g}$ sample at $25^{\circ} \mathrm{C}$ during 30 minutes. Suspensions were then centrifuged at $240 \mathrm{~g}$ for 10 minutes, and the supernatant was decanted. Additional solvent $(10 \mathrm{ml})$ was added to the centrifuge tube and the insolubles were washed twice with the respective solvents. The supernatant was stored at $4{ }^{\circ} \mathrm{C}$ until quantification. Insoluble residue from the water extraction was combined with solution of sodium chloride by the same extraction procedures. After successive extraction with distilled water, sodium chloride and ethanol solutions, the insoluble residue was extracted with sodium hydroxide solution, according Osborne (1924). Material remaining after the extraction with the four solvents was quantified using the Lowry method(1951).

\subsection{Antifungal Activity}


PDA plates were prepared using Petri dishes $(90 \times 20 \mathrm{~mm}$ in diameter) containing twenty five millilitres of PDA. Five milliliters of sterile water (control) or diluted crude proteic extract were added in the plates, and then inoculated with $4 \times 10^{5}$ spores of Rhizopus oryzae CCT 7560 , Aspergillus flavus CCT 1217 or Fusarium graminearum CQ 244. They were incubated at 22 ${ }^{\circ} \mathrm{C}$. The antifungal activity was evaluated by the glucosamine content, after 7 days. The percent inhibition of the glucosamine content of the target fungi was calculated according to the following formula. Percent inhibition $=(\mathrm{C}-\mathrm{T}) / \mathrm{C} \times 100$, where $\mathrm{C}=$ glucosamine content in the dry biomass on the control medium and $\mathrm{T}=$ glucosamine content in the dry biomass cultivated with the inhibitor. The experiments were carried out in duplicate.

\subsection{Glucosamine Determination}

The dry fungal biomass $(1 \mathrm{~g})$ was extracted with $5 \mathrm{~mL}$ of $\mathrm{HCl} 6 \mathrm{~mol} \mathrm{~L}^{-1}$ at $121{ }^{\circ} \mathrm{C}$ during 20 minutes. The hydrolyzed was neutralized with $\mathrm{NaOH} 3 \mathrm{M}$ and the reverse titration were carried out with $\mathrm{KHSO}_{4}\left(1 \mathrm{~g} 100 \mathrm{~mL}^{-1}\right)$. Finally, glucosamine was assayed by colorimetric method (Souza et al., 2011). The absorbance units were obtained spectrophotometrically (Varian Cary $100)$ at $530 \mathrm{~nm}$ and the concentrations were established with a glucosamine standard curve ( 0.01 to $\left.0.2 \mathrm{~g} \mathrm{~L}^{-1}\right)$. The measurements were carried out in triplicate and the results were expressed as glucosamine per $\mathrm{mg}$ protein.

\subsection{Statistical Analysis}

The difference of antifungal activity from the proteic extracts were evaluated by ANOVA and the means comparisons by Tukey's test. Differences were considered significant when $\mathrm{p}<$ 0.05 .

\section{Results and Discussion}

Albumin and glutelin represented the major soluble-protein fractions in rice grains (e.g. Figure 1). Wheat grains had high amounts of prolamine and glutelin, which is associated with their functional properties. The prolamine fraction represented $18.5 \%$ of the total soluble-protein in oat grains (Pagnussatt et al., 2011b) and this fraction was chosen consisting the literature mentions about enzymatic inhibitors from other vegetables are presented in this prolamine fraction (Figueira et al., 2003). It is important to remember that highest concentration of protein are in the other layers of the grains.

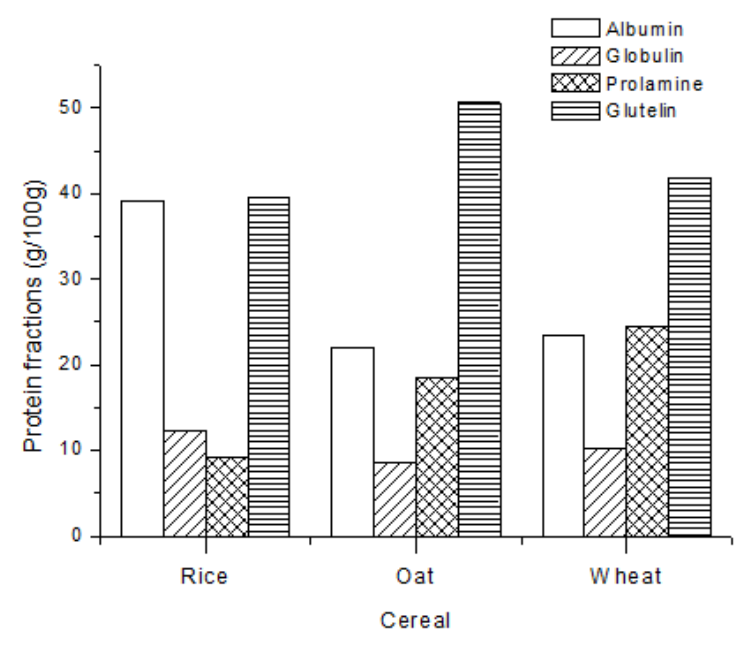

Figure 1. Protein fractions from the cereals 
Protein content on the prolamine fraction in crude extracts from rice, oat and wheat were 70.4 $\mathrm{mg} \mathrm{g}^{-1}, 131 \mathrm{mg} \mathrm{g}^{-1}$ and $179 \mathrm{mg} \mathrm{g}^{-1}$, respectively. The glucosamine produced by Rhizopus oryzae, Aspergillus flavus and Fusarium graminearum cultive on the control media or proteic extracts in the tests during $7^{\text {th }}$ days are in Table 1. The Fusarium growth on media containing wheat, oat and rice extract were observed, but the radial growth could not be determined because it presented an irregular growth.

Table 1. Glucosamine produced* (mg glucosamine/ g dry biomass) by the fungus Rhizopus oryzae, Aspergillus flavus and Fusarium graminearum in the presence of inhibitory extracts

\begin{tabular}{llllll}
\hline Glucosamine & \multicolumn{5}{l}{} \\
\hline \multirow{2}{*}{ Extracts } & Rhizopus oryzae & \multicolumn{2}{l}{ Aspergillus flavus } & \multicolumn{2}{l}{ Fusarium graminearum } \\
\cline { 2 - 6 } & $7^{\mathrm{o}}$ & $5^{\mathrm{o}}$ & $7^{\mathrm{o}}$ & $5^{\mathrm{o}}$ & $7^{\mathrm{o}}$ \\
\hline Control & $4.27^{\mathrm{I}}$ & $1.90^{\mathrm{b}, \mathrm{c}}$ & $1.11^{\mathrm{a}}$ & $1.4^{\mathrm{C}}$ & $0.2^{\mathrm{A}}$ \\
Rice & $8.65^{\mathrm{II}}$ & $1.35^{\mathrm{a}, \mathrm{b}}$ & $3.46^{\mathrm{d}}$ & $1.3^{\mathrm{B}}$ & $0.1^{\mathrm{A}}$ \\
Oat & $11.93^{\mathrm{III}}$ & $2.01^{\mathrm{b}, \mathrm{c}}$ & $4.21^{\mathrm{d}}$ & $0.8^{\mathrm{B}}$ & $0.13^{\mathrm{A}}$ \\
Wheat & $5.63^{\mathrm{I}, \mathrm{II}}$ & $0.93^{\mathrm{a}}$ & $2.34^{\mathrm{c}}$ & $1.2^{\mathrm{B}}$ & $0.15^{\mathrm{A}}$ \\
\hline
\end{tabular}

*Means followed by the same letter/number didn't differ statistically according to Tukey's test at the level of $95 \%$ when compared to control. Crude extract was tested at $40 \mathrm{mg}$ protein on each plate.

Proteic extracts have not showed inhibitory activity against Rhizopus oryzae, while to Aspergillus flavus and Fusarium graminearum the reduction was demonstrated by the lowest glucosamine level. The greatest Fusarium graminearum inhibition $(43 \%)$ was at the $5^{\text {th }}$ for oat extract followed by wheat extract $(15 \%)$ and the minor $(8 \%)$ when rice proteic extract was applied.

The wheat extract inhibited $52 \%$ the Aspergillus flavus multiplication at the fifth day and the rice extract presented $32 \%$ inhibitory activity. At $7^{\text {th }}$, the presence of the extract triggered fungal multiplication, showing that the inhibition was reversed or that the micro-organism used alternative pathways to obtained nutrients.

The study of protein solubility in cereals showed that prolamine fraction was different among them, however when its content was lower, higher inhibitory effect was verified against Fusarium graminearum; indicating an inversely proportional relation between them. $40 \mathrm{mg}$ of proteins were used and the $\mathrm{IC}_{50}$ values to inhibit Aspergillus flavus with oat extracts and Fusarium graminearum with wheat extracts were obtained. Velluti et al. (2004) and Pagnussatt et al. (2012b) also observed that multiplication of Fusarium graminearum species decreased when essential oils concentrations and phenolic compounds were increased.

Based on these data, new experiments will be carried out containing higher protein concentrations in order to find the $\mathrm{IC}_{80}$ for these micro-organisms with oat and wheat extracts and the $\mathrm{IC}_{50}$ for rice extracts. It is noteworthy that the present work is an in vitro study, where 
the inhibitors were concentrated to verify its action. Based on these results, in vivo study will be necessary to confirm its effect.

Fusarium graminearum tested in this study was isolated from wheat cultivated in southern Brazilian region and their toxigenic potential was demonstrated by DON production in culture medium. Its multiplication was demonstrated by the mycelial development decreased when the proteic extracts were applied in the culture media, suggesting a fungistatic effect, which in the wheat could be able to prevent deoxynivalenol production (Del Ponte et al., 2012).

Caruso et al. (2001) also indentified a glycoprotein isolated from wheat with inhibitory activity against Fusarium culmorum, which indicates a protective role against this pathogen attack in the field. The basic structure of this protein was studied and the authors concluded that it was able to enter in the fungal cell, leaving the wall intact. After it had become inserted in the host cell's cytoplasm, the antifungal activity of the protein was performed on the endogenous RNA (Bertini et al., 2009). Lee et al. (2007) reported that a rice protein could suppress Fusarium oxysporum, Fusarium solani, Aspergillus fumigatus and Aspergillus parasiticus growth too. There are reports similar to the observed in this experiment, when the proteic extracts decreased Fusarium graminearum CQ 244 multiplication in the crude form. However this is not according to the frequent occurrence of the genus and their mycotoxins in wheat (Del Ponte et al., 2012).

Kadozawa et al. (2002) found a possible enzymatic inhibitors effect during germination as a defense of maize against Fusarium verticillioides and Sitophilus zeamais. Figueira et al. (2003) also observed the ability from maize extracts inhibiting the Fusarium verticillioides growth, as well as insects, which often provide favorable conditions for fungal development. Besides cereals, other raw materials are used in antifungal activity tests, such as thyme and essential oils that were added on tomatoes and could inhibit the Aspergillus flavus. Microorganisms, such as Bacillus vallismortis, were also studied about its ability on preventing the pathogenic fungi proliferation, and it was showed that its extract inhibited in $90 \%$ and $50 \%$ the Alternaria alternata and Fusarium graminearum growth, respectively (Zao et al., 2010). These reports and others results suggest that plants protection mechanism based on amylase inhibitors seem to be more efficient against pathogenic organisms, such as Fusarium genus. In a similar way, in this study it was demonstrated that proteic extracts from cereals presented inhibitors ability against Fusarium graminearum and was able to inhibit by $50 \%$ the amylase activity from commercial enzyme Fungamyl ${ }^{\circledR}$ (Pagnussatt et al., 2012a) that represent a particular agronomic importance to food and feed grain production.

Different inhibitory effects observed against Rhizopus oryzae, Aspergillus flavus and Fusarium graminearum may be related to their class. Fusarium graminearum and Aspergillus flavus, classified as ascomycetes, with sexual spores that are stored in ascus shaped cells, such conformity generates a lower sporulation rate, being the proteic inhibitor more efficient due to the greater interaction time with the cells before the latence interval (Leslie \& Summerell, 2006). Rhizopus oryzae, classified as zygomicetes, present hypha without septa and their spores, resulting in high sporulation and rapid growth; such enzymatic pool allows faster responses to exogenous factors, resulting in a smaller interaction with the inhibitor. The low water activity in the cell could provide a minor efficiency to the proteic inhibitor too. 


\section{Conclusions}

The results suggest that the proteic extracts from cereal wastes may be considered a suitable alternative to chemical pesticides if they could be recovery from the matrix. Their employ alone or in a mix could attend the needs for safety and satisfy the demand for natural components as preservative and allow the environment protection against chemical contamination. In subsequent studies, antifungal activity will be evaluated considering other properties that allow their application to prevent fungal contamination.

Wheat extract were more efficient at the Aspergillus flavus inhibition, while the oat extracts inhibited Fusarium graminearum up to $50 \%$.

\section{References}

Armando, M. R., Dogi, C. A., Poloni, V., Rosa, C. A. R., Dalcero, A. M., \& Cavaglieri, L. R. (2013). In vitro study on the effect of Saccharomyces cerevisiae strains on growth and mycotoxin production by Aspergillus carbonarius and Fusarium graminearum. International $\begin{array}{lllll}\text { Journal of } \quad \text { Food } & \text { Microbiology, } & 161, & 182-188 .\end{array}$ http://dx.doi.org/10.1016/j.ijfoodmicro.2012.11.016

Bertini, L., Caporale, C., Testa, M., Proietti, S., \& Caruso, C. (2009). Structural basis of the antifungal activity of wheat PR4 proteins. FEBS Letters, 583, 2865-2871. http://dx.doi.org/10.1016/j.febslet.2009.07.045

Caruso, C., Chilosi, G., Leonardi, L., Bertini, L., Magro, P., Buonocore, V., \& Caporale, A. (2011). Basic peroxidase from wheat kernel with antifungal activity. Phytochemistry, 58, 743-750. http://dx.doi.org/10.1016/S0031-9422(01)00226-6

Dambolena, J. S., López, A. G., Meriles, J. M., Rubinstein, H. R., \& Zygadlo, J. A. (2012). Inhibitory effect of 10 natural phenolic compounds on Fusarium verticillioides. A structure, property and activity relationship study. Food Control, 28, 163-170. http://dx.doi.org/10.1016/j.foodcont.2012.05.008

Del Ponte, E. M., Garda-Buffon, J., \& Badiale-Furlong, E. (2012). Deoxynivalenol and nivalenol in commercial wheat grain related to Fusarium head blight epidemics. Food Chemistry, 132, 1087-1091. http://dx.doi.org/10.1016/j.foodchem.2011.10.108

Del Río, J. A., Báidez, A. G., Botía, J. M., \& Ortuno, A. (2003). Enhancement of phenolic compounds in olive plants (Olea europaea L.) and their influence on resistance against $\begin{array}{lllll}\text { Phytophthora sp. } & \text { Food } & \text { Chemistry, } & \text { 83, }\end{array}$ http://dx.doi.org/10.1016/S0308-8146(03)00051-7

Figueira, E. L. Z., Hirooka, E. Y., Mendiola-Olaya, E., \& Blanco-Labra, A. (2003). Characterization of a Hydrophobic Amylase Inhibitor from Corn (Zea mays) Seeds with Activity Against Amylase from Fusarium verticillioides. Biochemical and Cell Biology, 93, 917-922.

Kadozawa, P., Figueira, E. L. Z., \& Hirooka, E. Y. (2002). Inibidores de enzimas contra Fusarium moniliforme durante a germinação de milho. Semina: Ciências Agrárias, 23, 249-258.

Lee, S. H., Chang, K. S., Su, M. S., Huang, Y. S., \& Jang, H. D. (2007). Effects of some Chinese medicinal plant extracts on five different fungi. Food Control, 18, 1547-1554. 
http://dx.doi.org/10.1016/j.foodcont.2006.12.005

Leslie, J. F., \& Summerell, B. A. (2006). The Fusarium Laboratory Manual. USA: Ed. Blackwell Publishing: USA. http://dx.doi.org/10.1002/9780470278376

Lowry, O. H. (1951). Protein measurement with the folin-phenol reagent. Journal of Biological Chemistry, 193, 265-275.

Osborne, T. B. (1924). The vegetable proteins. (p. 154). London: Longmans.

Pagnussatt, F. A., Bretanha, C. C., Garda-Buffon, J., \& Badiale-Furlong, E. (2011a). Extraction of fungal amylase inhibitors from cereal using response surface methodology. International Research Journal of Agricultutal Science and Soil Science, 1, 428-434.

Pagnussatt, F. A., Garda-Buffon, J., Gutkoski, L. C., \& Badiale-Furlong, E. (2011b). Properties of protein fraction of rice, oat and wheat cultivars. Revista do Instituto Adolfo Lutz, 70, 184-191.

Pagnussatt, F. A., Meza, S. R., Garda-Buffon, J., \& Badiale-Furlong, E. (2012a). Procedure to determine enzyme inhibitors activity in cereal seeds. Journal of Agricultural Science, 4, 85-92.

Pagnussatt, F. A., Kupski, L., Darley, F. T., Filoda, P. F., Del-Ponte, E. M., Garda-Buffon, J., \& Badiale-Furlong, E. (2012b). Fusarium graminearum growth inhibition mechanism using phenolic compounds from Spirulina sp. Ciência e Tecnologia de Alimentos, 32, 1-6.

Sitanggang, A. B., Wu, S. H., Wang, S. S., \& Ho, C. Y. (2010). Effect of pellet size and stimulating factor on the glucosamine production using Aspergillus sp. BCRC 31742. Bioresource Technology, 101, 3595- 3601. http://dx.doi.org/10.1016/j.biortech.2009.12.084

Souza, M. M., Prieto, L., Ribeiro, A. C., Souza, T. D., \& Badiale-Furlong, E. (2011). Assesment of the antifungal activity of Spirulina platensis phenolic extract against Aspergillus flavus. Ciência e Agrotecnologia, 35, 1050-1058.

Velluti, A., Marin, S., Gonzalez, P., Ramos, A. J., \& Sanchis, V. (2004). Initial screening for inhibitory activity of essential oils on growth of Fusarium verticillioides, F. proliferatum and F. graminearum on maize-based agar media. Food Microbiology, 21, 649-656. http://dx.doi.org/10.1016/j.fm.2004.03.009

Viuda-Martos, Y., Navajas-Ruiz, Y., Fernandez-Lopes, J., \& Perez-Alvarez, J. (2008). Antifungal activity of lemon (Citrus lemon L.), mandarin (Citrus reticulata L.), grapefruit (Citrus paradisi L.) and orange (Citrus sinensis L.) essential oils. Food Control, 19, 1130-1138. http://dx.doi.org/10.1016/j.foodcont.2007.12.003

Zao, Z. Q., Wang, K., Brian, K., Liu, C., \& Gu, Y. (2001). Study of the antifungal activity of Bacillus vallismortis ZZ185 in vitro and identification of its antifungal components. Bioresource Technology, 101, 292-297. http://dx.doi.org/10.1016/j.biortech.2009.07.071 